\title{
Enterprise and Entrepreneurship
}

\section{in English Higher Education: 2010 and beyond}

\author{
Professor David Rae \\ ISBE \& Lincoln Business School, \\ University of Lincoln, \\ Brayford Pool, Lincoln LN6 7TS \\ email: drae@lincoln.ac.uk \\ Professor Lynn Martin \\ ISBE \& Manchester Metropolitan University \\ Dr Valerie Antcliff \\ Manchester Metropolitan University \\ Professor Paul Hannon \\ NCEE
}

Keywords: Entrepreneurship; Enterprise; Higher education; Public policy 


\begin{abstract}

\section{Objectives}

This article reports the results of a complete survey of enterprise education in all Higher Education Institutions (HEIs) in England, undertaken in 2010 by the Institute for Small Business \& Entrepreneurship (ISBE) on behalf of the National Council for Graduate Entrepreneurship (NCGE). The survey builds on prior work undertaken by the NCGE in England in 2006 and in 2007 (NCGE, 2007; Hannon, 2007).
\end{abstract}

\title{
Approach
}

The survey aimed to establish a complete picture of curricular and extra-curricular Enterprise \& Enterpreneurship education. The survey uses a similar structure to the previous survey, enabling comparison to be made with enterprise provision over the 2006-2010 period, as well as with the 2008 European survey of entrepreneurship in HE (NIRAS, 2009).

\section{Results}

The results provide a stocktake of enterprise education provision in participating HEls and highlight the connections in institutional strategies between enterprise education,

incubation/new venture support, graduate employability, innovation and academic enterprise. It reveals 'hotspots' and gaps in enterprise provision and offers 'benchmarks' for the sector.

\section{Implications}

The article offers a summary of the implications for the future development and sustainability of enterprise education in $\mathrm{HE}$, in relation to policy, funding and other changes in the sector. It also considers these issues in relation to recommendations from professional educators and Government policy for future development of enterprise in HE and comments on the policy impact of this work.

\section{Value}

The timing of the survey, in May-July 2010, was important as it reflected the end of a period of over ten years of sustained investment in enterprise in Higher Education by the previous Labour Government in the UK, through a range of funding initiatives. As major public expenditure reductions in support for $\mathrm{HE}$ and enterprise activity followed, this represented the 'high water mark' of publicly funded enterprise activity in the HE sector, and raised the question of how enterprise education and support activities would become sustainable for the future. The report analyses existing provision, assesses its development over the 2006-2010 period, and provides conclusions and recommendations covering future policy, development, resourcing, and sustainability of enterprise and entrepreneurship provision in Higher Education. 


\section{Enterprise and Entrepreneurship in English Higher Education: 2010 and beyond}

\section{Introduction}

This article is based on the results of the third survey of enterprise and entrepreneurship education and support activity within Higher Education in England and its subsequent influence on policy. The 2010 survey, which covered the 2009-10 academic year, was undertaken by a research team from the Institute for Small Business \& Entrepreneurship (ISBE) in partnership with the National Council for Graduate Entrepreneurship (NCGE) which subsequently became the National Centre for Entrepreneurship Education (NCEE). It enables limited comparisons to be made with the previous surveys undertaken in 2006 and 2007 by the NCGE, as well as at a European level through the 2008 European survey of entrepreneurship in HE (NIRAS, 2009).

The background and first of these surveys was descibed by Hannon (2007), identifying the need to map entrepreneurship provision in Higher Education at a regional level on behalf of the then Regional Development Agencies (RDAs). The 2007 report concluded that 'action needs to be taken to scale up and embed enterprise and entrepreneurship education to reach all students' and the 2010 survey showed the progress that had been made towards this goal.

The timing of the 2010 survey was significant. Higher Education Institutes (HEls: universities and specialist institutions) had benefited from considerable investment in enterprise over a sustained period through Higher Education Innovation Funding (HEIF) and other public funding streams, as shown in section 4 of the article. The scale of enterprise provision, both in the form of curricular awards and modules, and extra-curricular activities to support student and graduate entrepreneurship, had increased significantly over this period and markedly so since the first survey in 2006.

Although respondents to the survey were generally confident about future of enterprise activities, the results raised major questions over the future sustainability and funding for enterprise in HE. HEls were already being affected by funding reductions from HEFCE when they completed the survey, and it was anticipated that public spending reductions announced in the Comprehensive Spending Review and the Browne Review of HE (2010) would have significant implications for the HE sector; this was indeed the case. Public funding available to many (but not all) HEIs for enterprise-related activities was rapidly reduced by the UK Coalition government in 2010-11, representing a significant challenge to the sustainability of enterprise which is explored in the article.

These issues must be seen in the context of the UK economy, which continued to show very low levels of growth and recovery from the recession. The drive by the coalition goverment to 'rebalance' the economy from public to private sector growth, and to create new business ventures, sources of wealth creation and employment has many implications for universities. The role of the public sector in providing graduate employment may fall considerably, meaning that graduates will require higher levels of skills in business and in enterprise to compete in the changing job market. However, HE has a significant role in stimulating student and graduate entrepreneurship, and in educating and encouraging the entrepreneurs of the present and the future. Indeed, the review by Sir Tim Wilson into Higher Educationindustry collaboration initiated by the government identified as one of its criteria:

'An enterprising and entrepreneurial culture amongst university students and staff, where success in enterprise and entrepreneurship is celebrated, rewarded and promoted.' (Wilson, 2012: 14). The report highlighted the role of universities in promoting entrepreneurship, developing entrepreneurial skills, and measures to enhance employability.

\section{Definitions used in the article}

The report refers to both enterprise and entrepreneurship, and although closely associated these terms have distinct meanings which were used in completing the survey. 


\section{Enterprise:}

Students learning to use the skills, knowledge and personal attributes needed to apply creative ideas and innovations to practical situations. These include initiative, independence, creativity, problem solving, identifying and working on opportunities, leadership, and acting resourcefully to effect change. 'Enterprise' is also used as a noun to describe a small or new business or community venture.

\section{Entrepreneurship:}

The study of enterprise and entrepreneurs, including the practical and academic knowledge, skills and techniques used in being an entrepreneur. An entrepreneur is a person who identifies or creates and acts on an opportunity, for example by starting a new business venture or social enterprise. Entrepreneurship is a distinctive example of the application of enterprise skills and attributes in a specific context.

\section{Background and emerging issues in HE enterprise}

There is a continuing body of work which has explored and defined enterprise education in UK Higher Education, notably through contributions by Allan Gibb (2002), and by Garavan and O'Cinneide at a European level (1994); by Gorman et al in a ten-year study which covered early work in the field (1997); by Hannon (2004) in creating foundations for the subsequent NCGE initiatives (2004); by Matlay and Carey (2007) through a ten-year longitudinal study from 1995-2004; by Pittaway and Cope (2007); and by Pittaway and Hannon (2008) in assessing institutional strategies for HE enterprise education. Henry et al (2003) posed the essential, evergreen question: can entrepreneurship be taught?

There certainly continue to be debates on the purpose, goals, values and pedagogies of enterprise education, together with new thinking. Lewis (2011) concluded that entrepreneurship struggled to gain academic legitimacy at a moral, pedagogical and theoretical level, with the quality and focus of research being constraints. Controversially, she asserted that the unresolved tension of the twin goals of enabling students to become entrepreneurs or to understand and operate within an enterprising society, together with an over-dependence on government policy initiatives, have prevented this legitimacy. Blenker et al (2011) proposed a progression from existing paradigms of education to a new one of 'facilitating entrepreneurship as everyday practice' and, like Lewis, saw the development of 'an entrepreneurial mindset' being an outcome of the educational process. Jones (2011) argued the importance of entrepreneurship education being underpinned by an explicit teaching philosophy grounded on student learning, whilst Jones and Matlay (2011) developed a conceptual framework centred on the student and their dialogic relationships with educator, institution, educational processes and community. Emergent issues and challenges facing educators were reported by Carey and Matlay (2011), whilst Rae (2010) proposed that a 'new era' of responsible entrepreneurship and related education was required to address the failures of market capitalistic entrepreneurship which contributed to the financial crises of 2008-2011. These and other debates inform the intellectually diverse space of entrepreneurship education and educators, into which the survey, as an instrumental and relatively simplistic device, attempted to measure provision and assess the effectiveness of entrepreneurship education policy.

The previous surveys (Hannon, 2007; NCGE, 2007) created a mapping framework which addressed the effectiveness of sector-wide initiatives to develop both enterprise education and support for entrepreneurship in a way which both HEIs and policymakers could understand. Although the methodology and findings were not accepted by all, they also demonstrated that, whilst progress was being made, there was an underlying fragility of enterprise provision in $\mathrm{HE}$, in which lower than desirable levels of student engagement and institutional commitment were evident, with activities being highly dependent on public funding. These issues continue to be significant ones, and as public funding declines the question of whether entrepreneurship has both academic legitimacy and direct appeal to students remains important. 
One area of increasing interest is in the contribution by student-led enterprise societies. These existed with little more than anecdotal information available about them prior to Pittaway et al (2008) contributing an important initial study. Subsequently the formation of the National Consortium of University Entrepreneurs (NACUE) in 2008 to champion this movement led to growing awareness of the contribution of student-led enterprise organisations, which is reflected in both the 2010 survey and the 2011 HE White Paper (BIS, 2011). It has become clear that the role of students acting as entrepreneurs on campus in initiating and running network organisations can be dynamic in engaging students who may not be reached either by formal enterprise education or by institutional initiatives, but in being student-led they face challenges of sustainability and succession (NACUE, 2010).

NACUE, together with ISBE and Enterprise Educators UK, as independent membershipbased organisations, formed the Enterprise Alliance UK in 2010 as a means of presenting a united front to make the case for HE enterprise to government and other agencies. This gained a limited public profile but created dialogue between the constituencies of student-led, enterprise education, and entrepreneurship research communities, during a period of significant political, economic and funding changes with major implications for the sector. In addition to this survey, a product of this interaction was the development of an Enterprise Manifesto by Enterprise Educators UK (2010) and subsequently a Concordat agreed at the 2010 Cardiff International Enterprise Educators Conference. These gained widespread support from enterprise practitioners and were submitted to the new coalition Government for consideration in enterprise policy for $\mathrm{HE}$, which is covered in the conclusion to this article.

In summary, the context for the 2010 survey can be seen as significant. It occurred at a time of political change, immediately subsequent to the UK General Election which led not only to a change in government administration but to major changes in all aspects of policy affecting Higher Education, public spending and regional development. These changes were anticipated by respondents but the full implications were not yet known. Economically, the effects of the 2008-9 financial crises were starting to become apparent for institutions, students and communities. Conceptually, as outlined above,the research narratives surrounding entrepreneurship education were challenging some established positions and introducing new ideas. New organisations and movements were emerging to represent groups, such as educators and students, whose voices had not previously been heard in the prevailing discourse.

\section{Approach}

For the 2006 and 2007 surveys, a template had been provided online for HE respondents to complete as a document and then to submit. There had been extensive feedback and critique from respondents regarding the questions asked; the definitions used; the availability and reliability of data required; and the time and resource required to obtain data. The research team was highly aware of the need to improve the 'user interface' of the survey, in the interests of both maintaining a high response rate and enhancing the accuracy and reliability of the data submitted.

The previous survey tool was evaluated and significantly revised between January and April 2010. Given the need for consistency to allow comparison with the previous surveys, a range of questions and data fields had to be retained. User consultation and feedback enabled many questions to be clarified. Those which were problematic or burdensome to answer were eliminated where possible or simplified. The overall length and number of questions and data fields were significantly reduced. A pilot questionnaire was produced and circulated to a range of respondents for critique, following which further improvements were made.

The decision was made to replace the online template, which had given rise both to complaints and to inadvertant multiple submissions by responding HEIs, with a proprietary online survey tool. After reviewing available options in relation to the design requirements, 'Surveymonkey' was selected. This had the advantage of being familiar to many respondents, perceived as 'easy to complete', and offered greater reliability as well as basic analytical capability in comparison with the previous method. The survey questionnaire was set up on 
Surveymonkey and again tested with respondents in April-May 2010, enabling final changes to be made to the instrument.

Ensuring the highest response rate as well as data quality was a continuing priority. A dataset of HEIs, principal and respondent contacts was provided by NCGE. This was checked by the survey team who contacted HEls to verify or correct contact details. Finally the survey questionnaire was released online in June 2010 and all HEI contacts were asked to complete it by the end of July 2010. Responses were monitored online, which enabled contact to be made with HEls who had not opened the survey or who did not complete it. Calls to advise and help respondents were made by the survey team and as a result by the end of July 2010 116 HEls had responded. This was a lower response rate of $92 \%$ compared with $96 \%$ in 2007 and $94 \%$ in 2006. Although not every HEl completed all 67 questions in the survey, the response rates overall were sufficient for there to be a high degree of confidence in the results. The survey team were grateful to all those who responded to an in-depth and searching questionnaire at a busy time of year.

The previous surveys had included exclusively English HEls, following the territorial remit of HEFCE and NCGE. Data was collected on this occasion from those Scottish, Welsh and Northern Irish HEls who chose to participate in the study. However the proportion of responses was significantly lower, hence these have not been included in the results.

Following completion of the survey, the dataset was extracted from Surveymonkey and converted into an Excel format for initial analysis. It became evident that more complex analysis would be required, for which SPSS was used. Also, the dataset was examined carefully for duplicate entries, possible errors and omissions, of which there were many. These were checked with respondents and the data 'cleaned'. Initial analysis provided descriptive statistics with charts and graphs, enabling comparison with the previous surveys. More advanced analysis was performed to explore possible trends and correlations within the data. However it was found that concerns over data quality, with response rates to some questions lower than the overall response rate, limited the degree of advanced analysis which would provide reliable results.

\section{Summary of results}

In summary, the survey demonstrated the following results.

- $116 \mathrm{HEIs}$ in England responded to the survey from a total of 126, a response rate of $92 \%$

- $\quad 93 \%$ of responding HEls support student enterprise and graduate entrepreneurship

- Of these, $80 \%$ offered credit-bearing awards and modules in enterprise and entrepreneurship leading to academic qualifications while $91 \%$ provided extracurricular support for student and graduate entrepreneurship

- The rate of student engagement in enterprise (SER) increased to $16 \%$ in comparison with $7 \%$ in 2006 and $11 \%$ in 2007

- Data on male:female participation was not collected by all universities but for the $73 \%$ of those which did, for accredited courses, male student engagement was 59\% and female engagement $41 \%$

- However, of those reporting gender, 197 had no female students on their accredited enterprise programmes.

- $95 \%$ of the $91 \mathrm{HEls}$ who responded support students and graduates in new venture creation

Student engagement in enterprise (SER) was developed by Hannon (2007) to measure reported student involvement in enterprise education or extra-curricular activity, as a percentage of all students in $\mathrm{HE}$. It is a synthetic indicator, with accompanying limitations and possible distortions. For example, because it includes a gross figure for student involvement across an $\mathrm{HEI}$, there is no way of excluding students who participate in both an enterprise education course and one or more extra-curricular activities, so an unquantifiable degree of 'double-counting' is inevitable. However this may compensate for a likely degree of under- 
counting of students participating in extra-curricular events. As a measure, SER is not precise but it is a useful indicator of the general level of student involvement in enterprise, both institutionally and nationally.

\begin{tabular}{|c|c|c|}
\hline Overall indicators & 2010 & 2007 \\
\hline Response rate from HEls & $92 \%$ & $96 \%$ \\
\hline $\begin{array}{l}\text { Student Engagement Rate } \\
\text { (SER) }\end{array}$ & $16 \%$ & $11 \%$ \\
\hline Public Funding of E\&E* & $80 \%$ & $80 \%$ \\
\hline Average start-ups per HEI & 28 & 22 \\
\hline $\begin{array}{l}\mathrm{E \& E}^{*} \text { as part of the } \mathrm{HEI} \\
\text { Mission }\end{array}$ & $63 \%$ & $45 \%$ \\
\hline Male/Female Participation & $53 \% / 47 \%$ & $53 \% / 47 \%$ \\
\hline \multicolumn{3}{|l|}{$\begin{array}{l}\text { Institutional support and } \\
\text { provision: } \\
\text { In-Curricular provision }\end{array}$} \\
\hline $\begin{array}{l}\text { Business and Management } \\
\text { Delivery }\end{array}$ & $60 \%$ & $61 \%$ \\
\hline $\begin{array}{l}\text { Undergraduate/Postgraduate } \\
\text { Split }\end{array}$ & $78 \%: 22 \%$ & $80 \%: 20 \%$ \\
\hline Full-time/Part-time Split & $63 \%: 37 \%$ & 87\%:13\% \\
\hline \multicolumn{3}{|l|}{ Extra-Curricular provision } \\
\hline $\begin{array}{l}\text { Business Ideas/Planning } \\
\text { Support }\end{array}$ & $68 \%$ & $62 \%$ \\
\hline Business Start-Up Support & $19 \%$ & $17 \%$ \\
\hline Start-Up Funds & $66 \%$ & $53 \%$ \\
\hline \multicolumn{3}{|l|}{$\begin{array}{l}\text { Institutional policy and } \\
\text { infrastructure }\end{array}$} \\
\hline Explicit E\&E* Policy & $50 \%$ & $47 \%$ \\
\hline $\begin{array}{l}\text { Pro-Vice-Chancellor for } \\
\text { E\&E* }\end{array}$ & $60 \%$ & $46 \%$ \\
\hline Staff Development for E\&E* & $64 \%$ & $51 \%$ \\
\hline Student Enterprise Clubs & $67 \%$ & $52 \%$ \\
\hline E\&E* in mission & $63 \%$ & $45 \%$ \\
\hline Faculty level action plans & $40 \%$ & $36 \%$ \\
\hline Hot-desking facilities & $58 \%$ & $53 \%$ \\
\hline
\end{tabular}

Table 1 summarises the changes in key indicators over the three year period between 20072010. Owing to differences in the method of data collection and retention in the 2006 survey, there were too few points of comparison to include this survey in the table.

\section{European comparison}

The attempt was also made to compare results with a very detailed survey of entrepreneurship education undertaken with responses from 200 HEIs across 31 European countries in 2008 (NIRAS, 2009). The scope for comparison was again limited owing to differences in the questions and methodologies adopted by the surveys. 
The NIRAS survey report concluded that 5 million of the 21 million HE students in Europe were engaged in enterprise education, an engagement rate of $24 \%$. Although the data is gathered in different ways, this is broadly comparable with, and higher than, the SER for the UK of $16 \%$. This can be compared with the $48 \%$ of HEls in Europe offering enterprise education, compared with $77 \%$ of HEls in England offering either accredited or extracurricular enterprise education. This suggests that sufficient enterprise provision existed at the time of the survey in HEls in England, but that rates of engagement by students are markedly lower, and there is a need to make enterprise education and extracurricular activities available to as many students as possible. Also, the level and depth of activity may be lower for English compared with other European universities.

Since the report also commented unfavourably on the comparisons between activities in European and North American universities, it suggests a broader lack of international competitiveness in the English sector. However, in relation to its framework of six themes, the survey found that the UK's top-ranked 3 institutions in the survey performed best in relation to a transnational comparison of all 'top 3' institutions (NIRAS, 2009:93). In relation to funding for enterprise, $67 \%$ reported that Government funding was the primary source, which is broadly comparable with the $80 \%$ public funding cited by the NCGE survey.

\section{Key findings from the survey}

\section{Student engagement rate (SER)}

The student engagement rate is an indicator of the number of students participating in enterprise activity as a percentage of the total student population. The SER of $16 \%$ at national level was an increase on the $11 \%$ in 2007 . This increased to $24 \%$ when applied to the HEIs which responded to the survey. Only $9 \%$ of students were involved in enterprise skills development and $16 \%$ in enterprise activities overall, demonstrating that the significant majority of students were not participating in enterprise in a recognised way, either within or outside the curriculum. Although there may be some under-reporting of activity, since many HEls had worked hard on student engagement, badging 'enterprising' activities for example as employability or personal development, inertia and lack of interest from students, and in some measure from academic staff, could be as much a reason for this as institutional factors. Possibly it represents a lack of attractiveness of entrepreneurship to the broad student population. Table 2 illustrates the SER rates. 


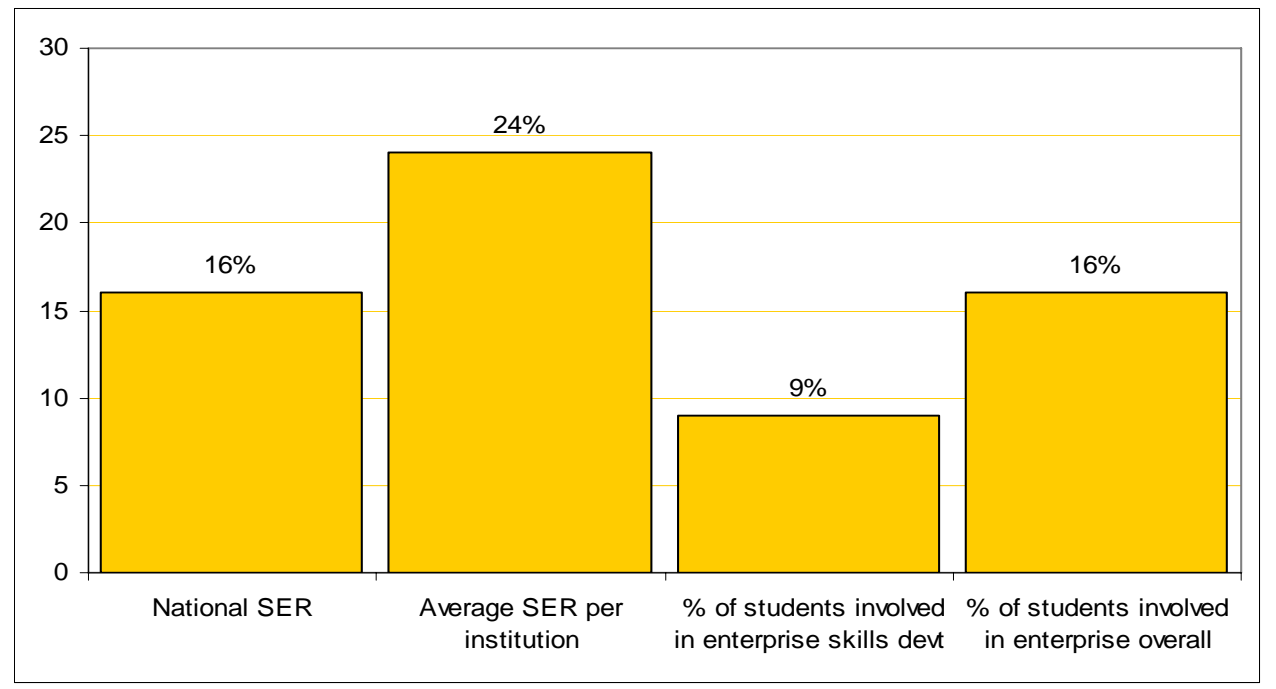

Table 2: Student Engagement Rate (SER)

Given this apparent lack of penetration, together with the important of stimulating enterprise in economic growth and in graduate employability, consideration may need to be given to going beyond a voluntaristic approach to enterprise provision, and moving to embed or 'design enterprise into' the curriculum for all HE students.

The graphs in the following sections show the percentages of participating HEls which offer support in the areas specified.

\section{In-curricular provision of Enterprise \& Entrepreneurship}

This includes full awards, offered by $80 \%$ of the sample, as well as specific enterprise and entrepreneurship modules, and modules in which enterprise and entrepreneurship comprised at least $50 \%$ of the content. These were offered by $70 \%$ of the sample. Of these, $51 \%$ of the provision is for undergraduate and $49 \%$ is at postgraduate level, whilst $44 \%$ is for full-time and $56 \%$ is for part-time students.

Business and management provided the lead faculty subject for $40 \%$ of the provision whilst other faculties led $60 \%$ of the provision. This indicated that non-business subjects had significantly increased either their involvement in enterprise education, or recognition of theit curricula as being enterprise-related, since in the 2006 survey $64 \%$ of provision was Business School-based. Table 3 illustrates the modes of enterprise curricula. 


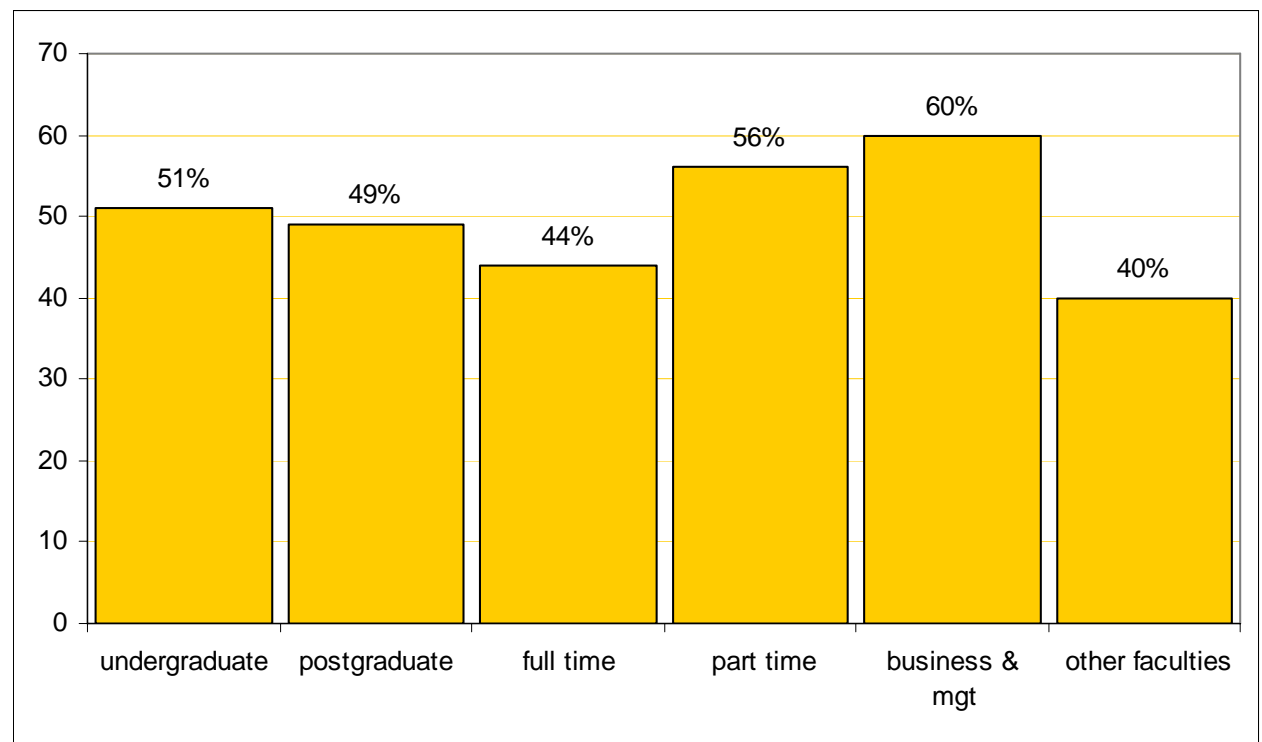

Table 3: In-curricular provision of Enterprise \& Entrepreneurship

\section{Extracurricular Enterprise \& Entrepreneurship provision}

Extra-curricular activities were offered by $91 \%$ of respondents. These are an essential means of raising student awareness of enterprise and providing opportunities to develop skills and confidence in practical ways. The survey tracked activities in idea generation and business planning; venture creation; enterprise skills development; networking events; and events targeted at specific themes, such as social enterprise, creative industries, science and technology, ethnic minorities and female students. The range, creativity and impact of extracurricular activities have increased, often supported by externally funded projects. The formation of student enterprise clubs and societies has increased from $52 \%$ to $67 \%$ of HEls, with activities supported nationally by NACUE from its launch in 2008 . In addition, facilities and resources provided by universities include incubators, dedicated centres and other provision as shown in the table 4.

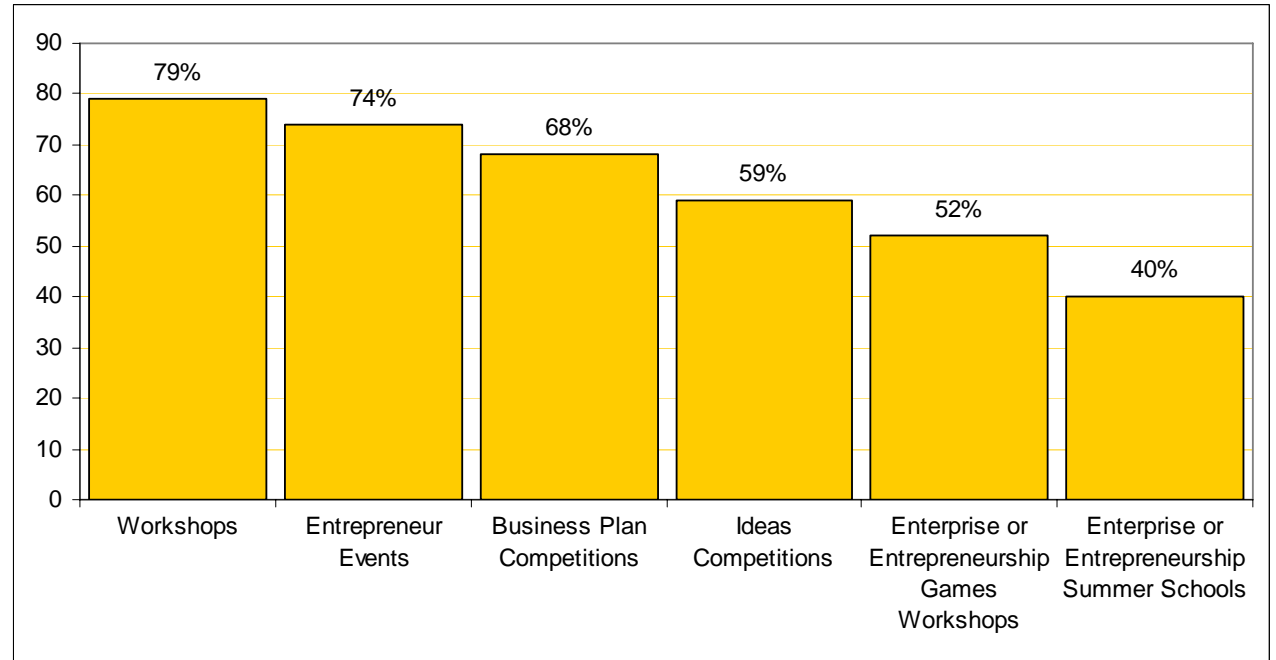

Table 4: Extracurricular Enterprise \& Entrepreneurship provision 


\section{Enterprise Skills Development}

The range of extra-curricular skills development programmes is also significant, as shown in table 5. This illustrates the 'crossover' between enterprise and employability activities which is helpful from a student and institutional perspective, but leads to definitional problems in distinguishing between them in a survey of provision.

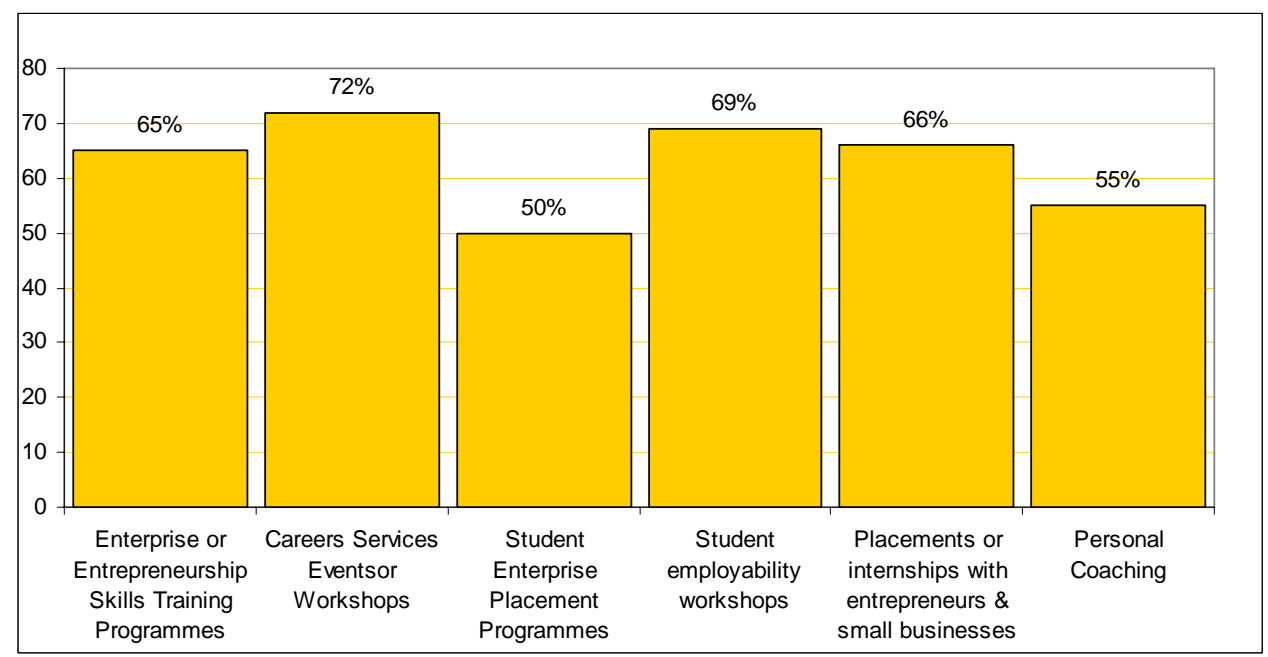

Table 5: Enterprise Skills Development

\section{Funding sources}

Enterprise and entrepreneurship activities draw on a range of funding sources, but with a high level of public funding. However, universities have committed significant contributions to enterprise from their own funding, and other non-public sources are also evident. This trend may be expected to increase as public funding is constrained. The percentages of Universities receiving funding from public and other sources are shown in tables 6 and 7 . 


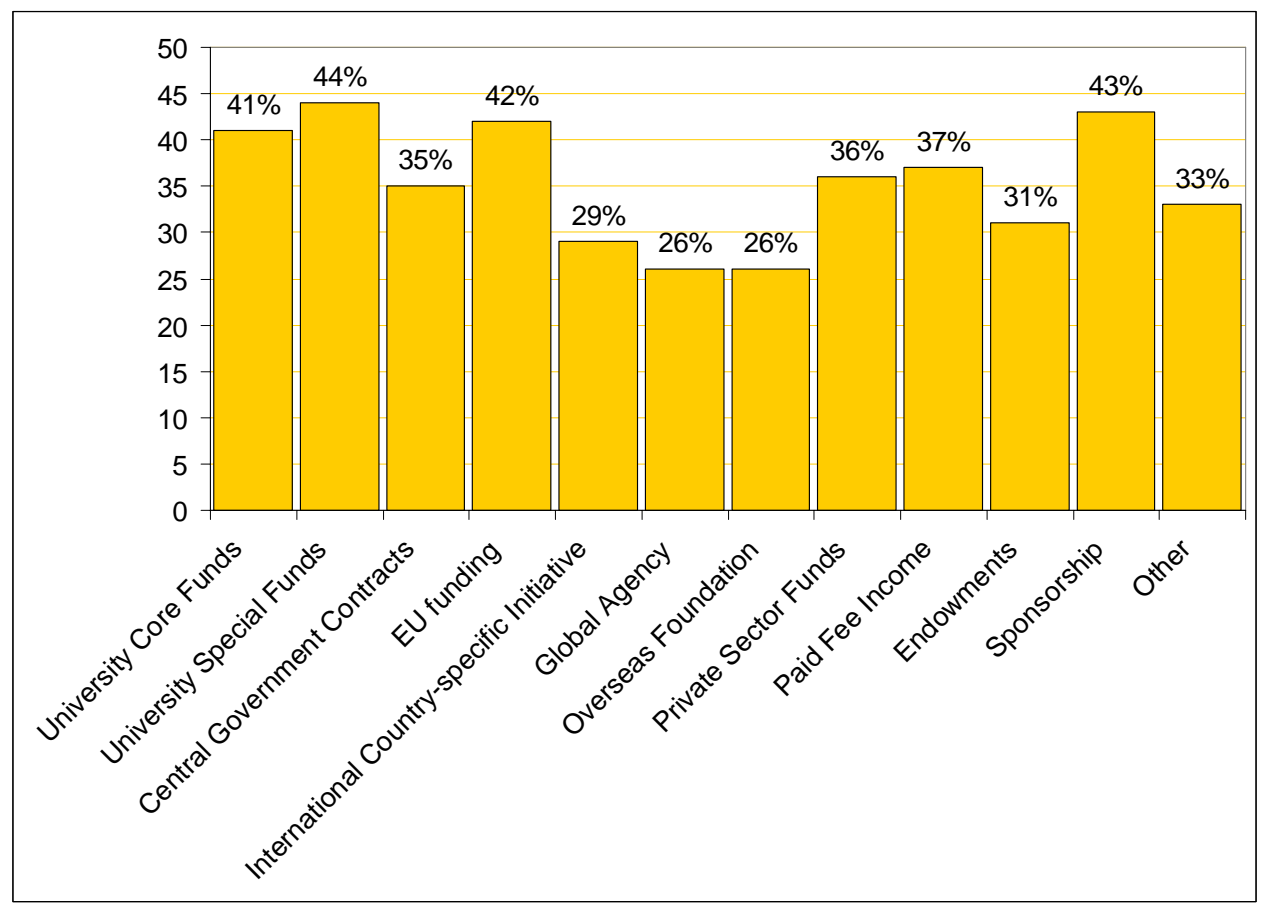

Table 6: HEls receiving funding for enterprise from all sources

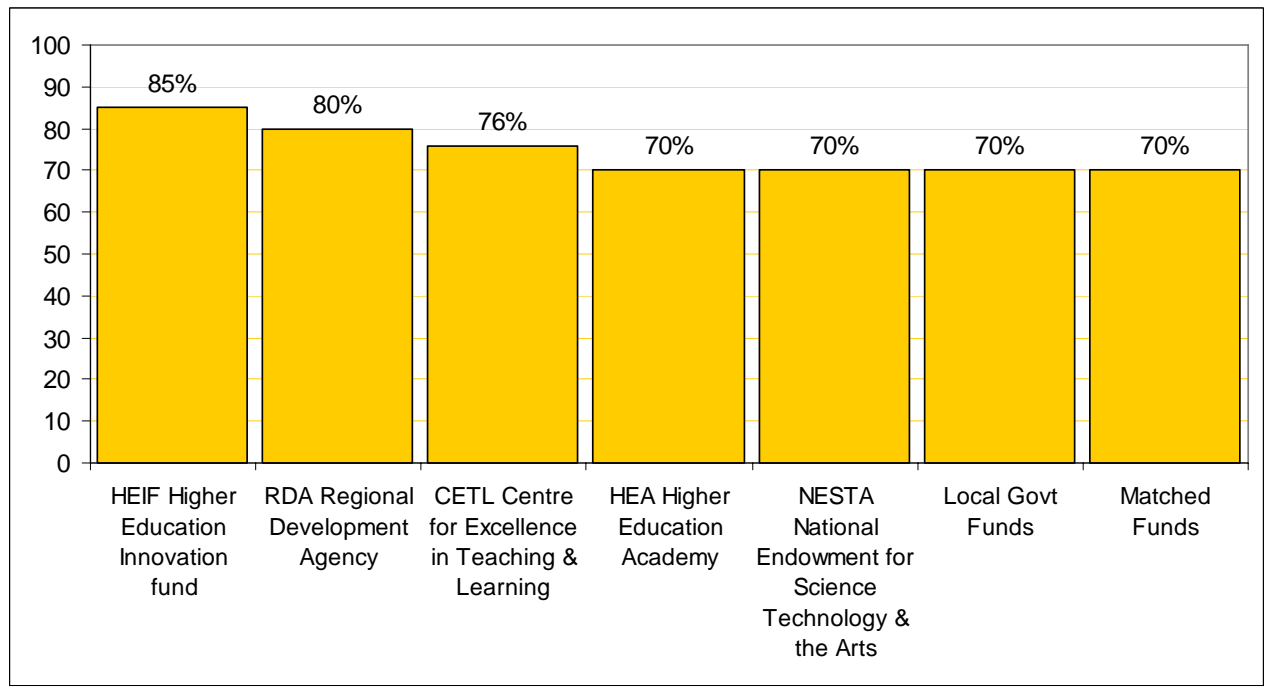

Table 7: Universities receiving funding from public sources

Of the sources of funding from the pubic sector, HEIF4 was the biggest single contributor. This ended in July 2011 and whilst the overall level is being maintained, a major reallocation for HEIF 5 rewards income generation but does not recognise the contribution which many HEls made to enterprise education and support activities through HEIF. As a result, there is now little incentive for HEIs to allocate HEIF 5 to activities which do not generate research or commercial income. Other principal sources which have ended included Regional Development Agency and CETL funding. The average amount spent per HEI in this area from HEIF was $£ 459,0432$. There is a significant danger that the end of these public funding 
sources has seriously impaired the continuity of enterprise education and support in a period when there is an increasing requirement to identify and access more sustainable sources of funding and to increase private sector and personal investments. Given the contribution that student enterprise can make to graduate employability and to venture creation, there is a need to address how it can be funded, for example within the curriculum from student fee income and from local economic development investment, such as Local Enterprise Partnerships (LEPS).

\section{Institutional policy, infrastructure \& staffing,}

The survey demonstrated that a significant majority of HEIs connect their policies on support for enterprise with those for employability, teaching and learning, innovation, research and knowledge transfer, and, surprisingly to a lesser extent, business incubation. Table 8 illustrates these connections.

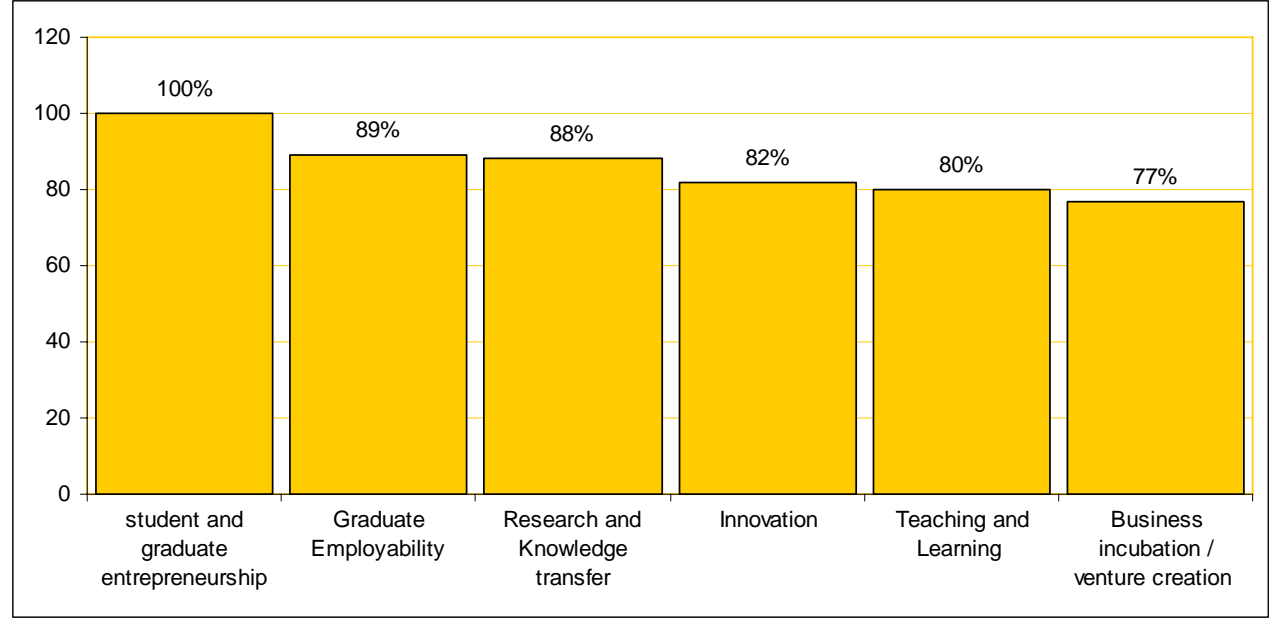

Table 8: Policies for Enterprise support

Levels of institutional infrastructure for enterprise vary significantly; for example, $60 \%$ have a Pro Vice-Chancellor responsible for enterprise, and a similar proportion (63\%) have enterprise embedded in the institutional mission. This compares with $71 \%$ at a European level (NIRAS, 2009). However other aspects vary. While an institutional policy on entrepreneurship is present in half of the respondent universities, only 33\% had an external advisory board, and $40 \%$ had faculty-level entrepreneurship action plans, possibly indicating that these were not seen as value-adding. External engagement was more of a priority. Enterprise in local schools and communities was supported by $63 \%$ and external engagement in communities by $70 \%$. However, effective institutional leadership of enterprise is an area for development at a crucial time.

Infrastructure to support student enterprise activity also varies widely across the sector, as shown in table $9.67 \%$ have a student-led enterprise club or society. There is a fairly strong level of support for staff development in enterprise (64\%), and $83 \%$ have appointed academic staff to teach enterprise, $44 \%$ have appointed professors and a similar number have visiting positions for entrepreneurs. 


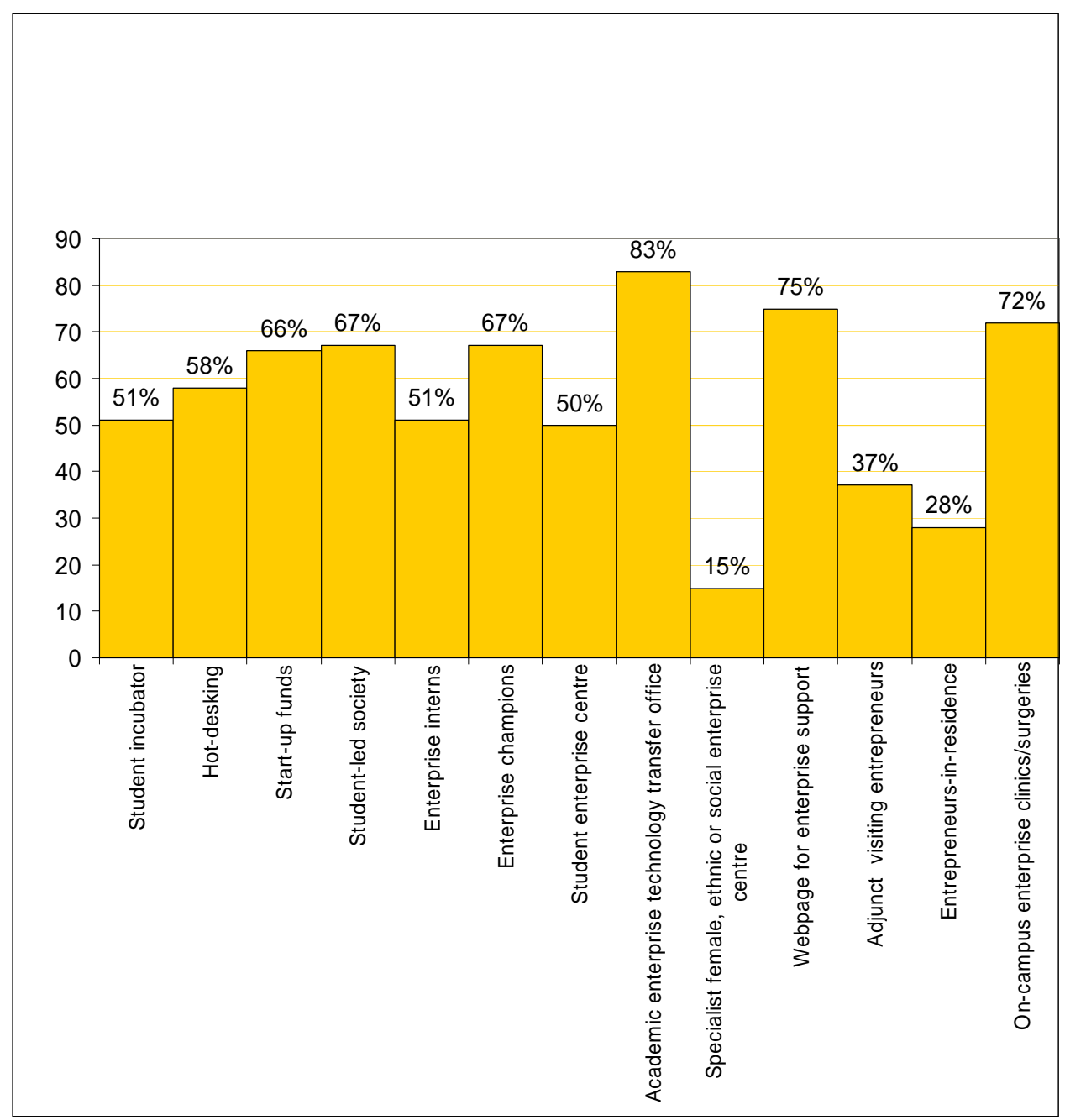

Table 9: HEI Infrastructure provision

\section{Venture creation}

$77 \%$ of HEls support students and graduates in creating new business ventures. HEls were asked how many student and graduate ventures had originated from them in 2008-9 and how many were estimated for 2009-10. Relatively few were able to provide reliable information, despite this information also being required for the Higher Education Business-Community Interaction (HEBCl) report (HEFCE, 2010), but the range varied from single figures up to over a hundred for each HEI per year, with the average per respondent being 22 in 2008/9 and 28 in 2009/10. It is important that HEls should aim to capture accurate information on this, since it provides a valuable indicator of the level of their entrepreneurial output. Responses showed that 2371 new ventures were created in 2008/9 and 3277 in 2009/10. This varied enormously across institutions, with 1750 claimed as the highest number of ventures created within a university and 1 as the lowest. Our concerns are supported by those of Chapman et al (2011:490) who, in a survey of university-related companies from London HEls, concluded that: 'few institutions had robust strategies to identify and monitor graduate start-ups and that official HE-BCl returns in this category could not be reliably reproduced.' 


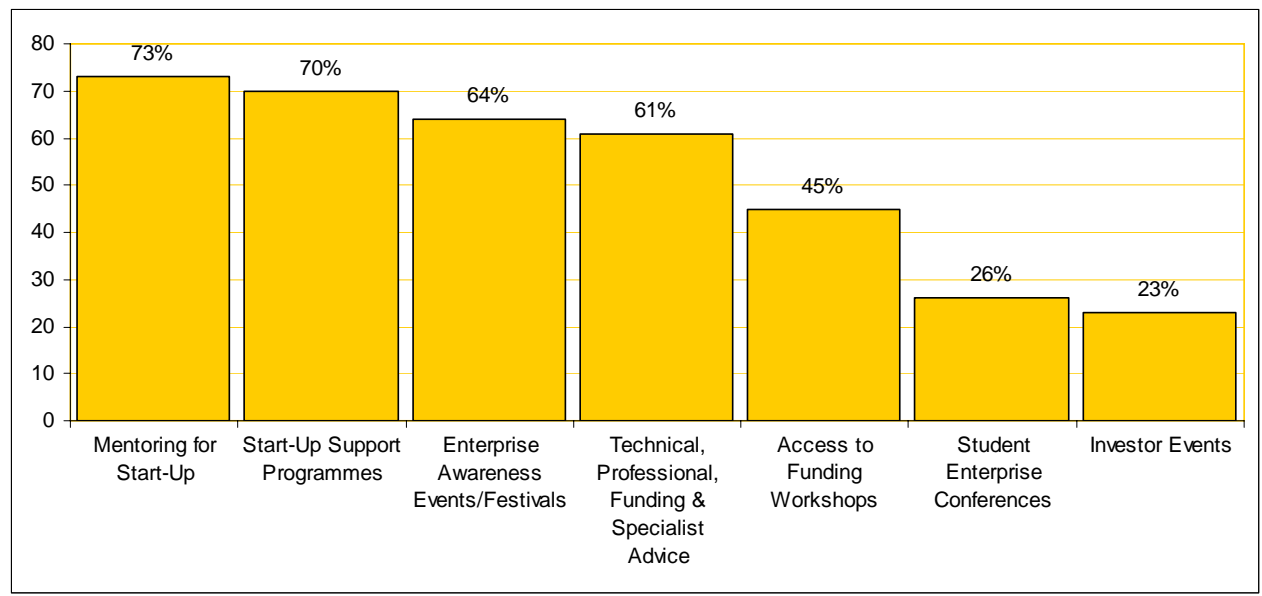

Table 10: Venture creation support activities

Future confidence in enterprise activity in $\mathrm{HE}$

Almost all respondents confirmed that student enterprise and entrepreneurial activities had increased over the past two years, and a similar number were, perhaps surprisingly, confident or very confident that educational activity would be sustained over the next two years. Most were also confident that extra-curricular and start-up enterprise support would be sustained, although some commented that this depended on funding. Regarding their ability to sustain staffing infrastructure for enterprise and entrepreneurship, most were again confident of their ability to maintain this with similar concerns regarding funding. Overall, there was a stronger measure of confidence in entrepreneurial activities and staffing than might have been expected given the context of public funding, suggesting that most HEIs saw these as priority activities. However the subsequent publication of the Browne Review and major changes in $\mathrm{HE}$ funding by the coalition government, including the HEIF re-allocation referred to, was expected to lead to significant reductions in enterprise provision and staffing during 2010-11.

\section{Regional findings by RDA regions}

The earlier surveys had a strong focus on reporting to Regional Development Agencies (RDAs) the level of entrepreneurial activity in regional HEls, by providing much data to analyse and compare patterns and trends at regional level. Although the coalition government announced the abolition of the RDAs at the time of the 2010 survey, regionality remains a valid construct for research and policy at a European level. It is retained in this article as it provides a useful means of comparing trends and performance across regional groups of HEIs. Table 11 shows significant variation both across and within regions in terms of student engagement rates, with some universities appearing to have surprisingly low SERs.

\begin{tabular}{|l|c|r|r|}
\hline RDA & \% of students in England & Total no of HEls per region & \multicolumn{1}{c|}{ Regional SER } \\
\hline AWM & $8 \%$ & 9 & 7.36 \\
\hline EEDA & $5 \%$ & 7 & 14.66 \\
\hline EMDA & $8 \%$ & 10 & 19.99 \\
\hline LDA & $27 \%$ & 31 & 7.08 \\
\hline NWDA & $13 \%$ & 14 & 6.03 \\
\hline ONE & $7 \%$ & 5 & 14.56 \\
\hline SEEDA & $15 \%$ & 18 & 7.68 \\
\hline SWRDA & $9 \%$ & 14 & 13.46 \\
\hline YF & $10 \%$ & 11 & 13.46 \\
\hline & $(\mathrm{n}=1,815,606)$ & & \\
\hline
\end{tabular}

Table 11: Student Engagement Rates by RDA Region (\%) 
While East Midlands shows the highest numbers of student engagement in enterprise via the SER, South West has the highest institutional rate of HEI and North West has the individual university with the highest SER. One RDA felt the result did not reflect the considerable investment and efforts they had invested in HE enterprise, but the reason for this disparity must lie in the results reported by the HEls in the region. The figures for LDA were affected by the low response rate by only $52 \%$ of London HEls to the survey.

When the gender of students on enterprise courses is considered, there is a significantly higher proportion of male students on accredited programmes in enterprise than female, as revealed in table 12 . This is exacerbated by some courses being all male, none being all female. There are however, some programmes with high numbers of women, which account for the male: female ratio appearing more favourable than it would otherwise have done. Given that female student participation in HE significantly exceeds male (HESA 2011), this should cause concern if gender parity is to be an aim in business start up and growth. Figures for ethnicity were not provided by sufficient universities to enable analysis. However this gender disparity raises concerns about diversity, given both the potential talent within ethnic minority populations, and the significant growth trend in female entrepreneurship within the UK, which should be supported by HE enterprise. It may suggest that enterprise is seen as a masculine interest, hence there may be a need to ensure enterprise is promoted as a desirable female cultural norm, both generally and in courses where there are high proportions of female students.

\begin{tabular}{|l|c|c|c|c|c|c|} 
& $\begin{array}{c}\text { No of } \\
\text { HEls } \\
\text { reporting } \\
\text { accredited } \\
\text { enterprise } \\
\text { courses }\end{array}$ & $\begin{array}{c}\text { Regional \% } \\
\text { female } \\
\text { students } \\
\text { enterprise } \\
\text { accredited }\end{array}$ & $\begin{array}{c}\text { Regional \% } \\
\text { male } \\
\text { students } \\
\text { enterprise } \\
\text { accredited }\end{array}$ & $\begin{array}{c}\text { Female } \\
\text { average \% } \\
\text { per HEl }\end{array}$ & $\begin{array}{c}\text { Hels } \\
\text { HEls } \\
\text { reporting } \\
\text { gender }\end{array}$ & $\begin{array}{c}\text { oporting } \\
\text { gender } \\
\text { with no } \\
\text { females } \\
\text { on } \\
\text { accredited } \\
\text { enterprise } \\
\text { course }\end{array}$ \\
\hline AWM & 9 & 21.87 & 78.13 & 25.08 & 7 & 2 \\
\hline EEDA & 7 & 38.46 & 61.54 & 30.29 & 6 & 1 \\
\hline EMDA & 10 & 45.07 & 54.93 & 41.34 & 8 & 1 \\
\hline LDA & 18 & 40.84 & 59.16 & 29.97 & 16 & 5 \\
\hline NWDA & 9 & 38.11 & 61.89 & 38.11 & 8 & 2 \\
\hline ONE & 4 & 17.76 & 70.56 & 14.22 & 4 & 1 \\
\hline SEEDA & 18 & 28.33 & 71.67 & 33.61 & 16 & 4 \\
\hline SWRDA & 10 & 40.13 & 59.87 & 41.78 & 8 & 4 \\
\hline YF & 11 & 22.35 & 77.65 & 27.35 & 11 & 3 \\
\hline
\end{tabular}

Table 12: Female and male participation in enterprise courses

\section{Findings by size of HEI}

When the size of HEls by student numbers is considered, the survey suggests that student engagement generally decreases as $\mathrm{HEI}$ size increases, from a high level in HEls with very small student numbers, such as specialist institutions. This suggests that the effect of enterprise 'champions', networks and events can be quite pronounced in small institutions. As shown in table 13, the levels in small and very large HEls are quite similar, but with a distinct 'dip' in medium and large-sized HEIs.

\begin{tabular}{|lcccc|}
\hline HEI Category (no. of & No in this & $\begin{array}{c}\text { Average } \\
\text { category } \\
\text { students) }\end{array}$ & $\begin{array}{c}\text { numbers of } \\
\text { enterprise } \\
\text { engagement }\end{array}$ & average SER \\
micro (up to 1000) & 11 & 9 & 704 & 71 \\
\hline
\end{tabular}




\begin{tabular}{|lcccc|}
\hline small $(1001-10000)$ & 38 & 33 & 855 & 27 \\
medium $(10001-20000)$ & 31 & 27 & 2830 & 17 \\
large $(20001-30000)$ & 25 & 22 & 2840 & 11.32 \\
very large $(30000+)$ & 11 & 9 & 10732 & 29.25 \\
\hline
\end{tabular}

Table 13: Student engagement by HEI size

\section{Conclusions}

This section summarises the implications of the study and the actions it recommended under six themes which relate to the broader educational and policy context. Universities have critical roles in producing knowledge, educating graduates with entrepreneurial mindsets, and in enacting innovation and entrepreneurship. Many HEls have demonstrated their ability to act as hubs, interacting with private and public sector partners to stimulate entrepreneurial activity around them (HEBCl, 2011). They have a major contribution to make both to the recently formed Local Enterprise Partnerships, and at national and international levels to innovation and economic development. This can only be achieved through developing entrepreneurial people, as described in this study. But it is also clear that in the resource-constrained and incentivised environment of HEIF funding, investment in entrepreneurship within universities must show a return, and for this reason the outputs from entrepreneurial activity in the HE sector are vitally important.

\section{Student engagement}

Student engagement in enterprise has increased to $6 \%$ nationally across all HEIs, or an average of $24 \%$ for each institution participating in the study. Whilst this appears to be an encouraging improvement from the $7 \%$ first recorded in 2006 , it nevertheless means that a significant majority of students either did not choose, or did not have the opportunity, to participate in enterprise and entrepreneurship, and engagement in English universities may even have been lower than the European average. The voluntaristic, optional approach adopted in a significant number of HEls could be failing students, who may realise too late that they missed out on enterprise whilst at university and subsequently are disadvantaged in the increasingly competitive job market. Alternatively, it could mean that students are aware of enterprise options, but do not consider them sufficiently attractive or relevant. The survey again confirms that the range of enterprise provision exists, but there is a gap in participation levels, and possibly a mismatch between student orientation and the provision available.

Given the extensive media coverage of entrepreneurial activities as well as the proliferation of online business platforms which can be accessed through tablet PC applications, such as Apple and Google Apps, it may be that students' entrepreneurial learning is increasingly individual and online, rather than course-based, and invisible to this type of survey.

\section{Integrating \& embedding enterprise for all students}

Given the need for graduates of all subject disciplines to possess not only enterprising skills, but also attributes of self-efficacy and flexibility, should every HEI consider ensuring that all students are given the opportunity to experience enterprising learning and skill development within their degree? There is a need to build on, rather than repeat, enterprise in the school curriculum. There are many successful examples of embedding enterprising learning into the curricula of non-business subjects, such as in art \& design, science and healthcare. This needs to become the norm, in the interests of graduates, employers and HEls themselves, as the $\mathrm{CBI}$ recommended $(\mathrm{CBI}, 2009)^{1}$. Also, universities need to examine their approach to attracting male and female students to enterprise and keep records which demonstrate gender and ethnic access and diversity, for both accredited and extra curricular programmes.

\section{Graduate employability and enterprise}

\footnotetext{
${ }^{1}$ The CBI report 'Stronger together; Universities and businesses in turbulent times' (2009) recommended that 'business and universities must ensure that all students develop employability skills while still at university. These skills are self-management, teamworking, business and customer awareness, problem solving, communication and literacy, numeracy, and the application of information technology.' Enterprise makes a strong contribution to the development and practice of these skills.
} 
The dynamics of the graduate employment market are changing rapidly, and a decline in the previous healthy levels of demand from public sector organisations for graduates has occurred, whilst private sector employment is likely to increase as the economy recovers from recession. It is known that enterprising graduates are in general more employable. Many more graduates will need to develop career options in starting their own businesses, working in small firms, in the private sector more generally, and in social enterprises and third sector organisations. The survey report proposed that entrepreneurship should be seen as a graduate employment outcome in the Destination of Leavers from HE (DLHE) annual survey, which had not previously been the case but will be adopted in future. The graduate career and future employability need to be reconceptualised as being fundamentally about enabling graduates to be flexible and entrepreneurial in launching and developing their careers rather than seeking jobs; the alternative may be high levels of graduate underemployment and unemployment, with costly economic and social consequences.

\section{Entrepreneurial productivity and venture creation}

The survey confirms the range of provision, activities and engagement which exist. If this is considered as investment in the future entrepreneurial capital of graduates, the value created or return on this investment also needs to be known. The numbers of graduates exposed to entrepreneurial experience, who have developed skills and confidence in enterprise, is one indicator. Another is the number of students and graduates who start a venture either whilst at University or shortly afterwards. Many HEls were able to provide this data, but not all was reliable, and it was not easy for all to do so.

HEls also need to be able to demonstrate the application and impact of graduate entrepreneurship which results from their investment and public investment in enterprise education and extracurricular activities. Tracking this is not easy but there is applicable expertise within the sector, whilst the assessment of 'value added' to graduates and by them to economic activity will become more important as HEIs are subjected to the scrutiny of Key Information Sets, for example. Graduate self-employment, venture creation, internships and employment within small firms and in social enterprises are examples of indicators which may be used, as is participation within Knowledge Transfer Projects and research and innovation projects after graduation.

\section{Local collaborations for enterprise}

University entrepreneurship should be a major contributor to 'economic rebalancing' and growth in cities and counties, and Local Enterprise Partnerships may provide one forum for this. However there are many areas across England where economic activity and graduate employment are likely to be negatively affected in the medium or longer term by the aftermath of the recession and reductions in public sector expenditure. Previous experience in enterprise education has shown that collaboration between groups of HEls, involving other partners such as Chambers of Commerce, other business organisations, local authorities and schools, for example, can achieve greater results, of lasting benefit, more cost-effectively then individual HEls acting alone, such as in the SPEED project (Rae, 2009) ${ }^{2}$. There should be incentives and support for HEls to collaborate with each other and with other local economic partners to increase the positive impact of enterprise education and entrepreneurship support, making this accessible to local small firms as well as students and graduates. However government policy on HE strongly encourages competition and does not reward collaboration (BIS, 2011).

\section{Leadership for enterprise}

A significant number of HEls, but a minority overall, demonstrate leadership of enterprise in holistic ways across the institution ${ }^{3}$, enabling enterprise in all subject areas and connecting curricular, extra-curricular and external engagement with business and community enterprise effectively. The leadership, culture, management structures and value systems of some, but by no means all, HEls enable this. Those which exhibit an entrepreneurial team of academic and professional staff acting in a co-ordinated way across and outside the institution are much more able to achieve this. In many HEls, individuals or small groups within one faculty or

\footnotetext{
${ }^{2}$ For example the SPEED project funded by HEIF in 2004-6; subsequent venture creation projects such as Enterprise Inc. in the East Midlands; Science Enterprise Challenge networks from 2001-4.

${ }^{3}$ As shown in the THES 'Entrepreneurial University of the Year' award, sponsored by NCGE.
} 
support department act as champions of enterprise, but there is often fragility associated with lack of institutional commitment, resources, leadership and ability to connect enterprise and entrepreneurship effectively across the organisation. Ultimately, enterprise in HEls only works because of the commitment and effectiveness of enterprising staff, who are often vulnerable to loss of employment or redeployment from funding changes, especially in smaller HEls.

Finally, many HEIs (50\% of respondents) have an explicit policy as an institutional commitment to entrepreneurship and enterprise education. If this survey is repeated in future years, it will be interesting to see how the landscape has changed and the extent to which economically sustainable approaches to enterprise development have developed to reduce dependence on public funding. The degree to which student-owned activities such as enterprise societies, which the coalition government is keen to support, have become embedded should be assessed. Overall, the entrepreneurial university (Clark, 1998; Gibb, 2005) has become a widely accepted, but not always clearly understood idea in HE since the first survey in 2006. In the new era of HE, following the Browne review of funding, there is probably no alternative to becoming an entrepreneurial university.

\section{Impact on public policy}

The publication of the Higher Education White Paper in June 2011 included recommendations for government policy relevant to this study (BIS, 2011). Following the report summarising the results of this survey (NCGE 2010), there was a period of briefing and consultation with the Department of Business Innovation and Skills and other agencies on the role of enterprise in $\mathrm{HE}$, to which documents referred to earlier contributed. The outcome was a short section on Enterprise and Higher Education, with two recommendations. The first was to develop the role of student enterprise societies, with the 'challenge' 'to embed a society in all universities in England and at least half of further education colleges' (BIS, 2011: 44). This was the outcome of active engagement by NACUE and associated organisations, including the NCGE, Enterprise Educators UK and ISBE, to promote the role and spread of enterprise societies. The Minister for Small Business gave his personal endorsement and pledged official funding support. The second recommendation, worded as 'support' for the first, was for a group convened by the QAA to develop curricular guidance for universities on 'the skills and knowledge, attitude and approach that students should acquire through enterprise education' (BIS, 2011: 45). This initiative was not supported by any funding, leaving implementation as a matter for individual HEls to address in a period of major systemic change in the funding and nature of $\mathrm{HE}$. The working group included representation from the survey team and was informed by the results of this survey. The guidance, which has been published for consultation,

"offers a framework for development and assessment of enterprise and entrepreneurship behaviours, attributes and skills which, taken together, contribute towards the development of an entrepreneurial mindset and entrepreneurial effectiveness." (QAA, 2012:4).

Simultaneously, the Wilson Review of Business-University Collaboration (2012) highlighted the role of HEls in developing enterprise skills and promoting entrepreneurship in the wider context of graduate employability. Commenting on the need for measurement of enterprise education, Wilson advised caution which is relevant to future research activity:

"Presently, growth in the enterprise and entrepreneurship education agenda is strong and increasingly innovative. Measuring what exists will focus universities upon the activities being measured; it has a strong potential to inhibit innovation, not to drive it. If enterprise culture, which is the essence of successful enterprise education, is to be measured, it cannot be a simple process; it requires a rigorous and comprehensive study, engaging with students and universities during the process." (Wilson, 2012: 50).

So it is clear that the 2010 survey played a useful role in informing future policy on enterprise in $\mathrm{HE}$ under the coalition government, and helped to ensure that its continuing importance was recognised. It is also evident that the long period of significant public support for enterprise initiatives in $\mathrm{HE}$, which had been a feature of the previous administration, ended conclusively in 2010. Therefore the challenge for institutions and educators is how to develop approaches for student enterprise and entrepreneurship education which are sustainable both academically and financially, and which engage students, sponsors and communities 
effectively. Given the continuing economic difficulties facing the UK, the need for HE to stimulate and support entrepreneurial development, economic renewal and growth has never been more pressing. The effectiveness of their response to this challenge will be a topic for future research, which needs to take note of the recommendation above from the Wilson Review.

\section{References}

Blenker, P., Korsgaard, S., Neergaard, H.,\& Thrane, C. (2011).

'The Questions we care about: Paradigms and Progression in Entrepreneurship Education'. Industry \& Higher Education, vol 25, no 6, pp417-428.

Browne, J. (2010), Securing a sustainable future for Higher Education: an independent review of higher education funding \& student finance.

Business Innovation \& Skills (2011), Higher Education: Students at the heart of the system, BIS, London.

Carey, C. \& Matlay, M. (2012).'Emergent Issues in Enterprise Education', Industry \& Higher Education, vol 25, no 6, pp441-450.

CBI, (2009). 'Stronger together; Universities and businesses in turbulent times', CBI, London. Chapman, D. Lawton Smith, H., Wood,P., Barnes, T., Romeo, S. (2011). University Enterprise: the growth and impact of university-related companies in London, Industry \& Higher Education, vol 25, no 6, pp483-492.

Clark, B.R. (1998). Creating entrepreneurial universities: organizational pathways of transition, IAU Press/Elsevier, Oxford.

Enterprise Educators UK (2010) The manifesto for the new government of the UK. Enterprise Educators UK, Sheffield.

Garavan, T.N. and O'Cinneide, B., (1994). Entrepreneurship Education and Training Programmes: A Review and Evaluation - Part 1. Journal of European Industrial Training, Vol 18 No. 8, pp 3-12; Part 2, vol 18 no.11,pp13-21, MCB University Press Limited

Gibb, A. (2002), "Creating Conducive Environments for Learning and Entrepreneurship; Living With, Dealing With, Creating and Enjoying Uncertainty and Complexity", Industry and Higher Education, Vol.16 No. 3, pp.135-148.

Gibb, A. (2005) Towards the Entrepreneurial University: Entrepreneurship Education as a lever for change, National Council for Graduate Entrepreneurship, Policy Paper \#003, Birmingham

Gorman, G.,Hanlon,D.,King.W.,(1997). Some research perspectives on entrepreneurship education, enterprise education and education for small business management: a ten-year literature review, International Small Business Journal, vol.15, no.3, p56-77.

Hannon, P., (2004), Making the journey from student to entrepreneur: a review of the existing research into graduate entrepreneurship, NCGE, Birmingham.

Hannon, P (2007) Enterprise for all? The fragility of enterprise provision across England's HEls, Journal of Small Business \& Enterprise Development, Vol 14 no 2, pp183-210. HEFCE (2010) Higher Education - Business and Community Interaction Survey 2008-09, HEFCE, London.

HESA (2011) Students in Higher Education Institutions 2009/10, HESA,Cheltenham. http://www.hesa.ac.uk/index.php?option=com_content\&task=view\&id=1897\&Itemid=239 Henry, C., Hill, F. and Leitch, C., (2003) Entrepreneurship Education and Training, Aldershot: Ashgate Publishing Ltd HM Treasury (2010), Spending Review 2010, HM Treasury, London.

Jones, C. (2011). Teaching entrepreneurship to undergraduates, Edward Elgar, Cheltenham. Jones, C. \& Matlay, H. (2011). Understanding the heterogeneity of entrepreneurship education: going beyond Gartner. Education \& Training 53, 8/9, pp692-703.

Lewis, H. (2011) A Model of Entrepreneurial Capability based on a Holistic Review of the Literature from Three Academic Domains, Industry \& Higher Education, vol 25, no 6, pp429440.

Matlay and Carey (2007) Entrepreneurship education in the UK: a longitudinal perspective, Journal of Small Business \& Enterprise Development, Vol 14 no 2, pp252-263.

NACUE, (2010).Student-led enterprise organisations, NACUE, London.

NCGE (2007) Enterprise and entrepreneurship in Higher Education, NCGE, Birmingham 
NCGE (2010) Enterprise and entrepreneurship in Higher Education 2010 National Survey report, NCGE, Birmingham

NIRAS (2009) Survey of Entrepreneurship in Higher Education in Europe, NIRAS consultants. Penaluna, A., Smith, K., Price, A. (2010) IEEC 2010 Concordat, agreed at the 2010 International Enterprise Educators Conference, Cardiff.

Pittaway, L. and Cope, J., (2007), 'Entrepreneurship Education - A Systematic Review of the Evidence', International Small Business Journal, Vol. 25, No. 5, p. 477-506.

Pittaway, L. and Hannon, P.(2008) Institutional strategies for developing enterprise education; A review of some concepts and models, Journal of Small Business and Enterprise Development. Vol. 15, Iss. 1; p. 202.

Pittaway, L., Rodriguez-Falcon, E., Aiyegbayo, O., King , A. (2011) The role of entrepreneurship clubs and societies in entrepreneurial learning, International Small Business Journal vol. 29 no. 1 pp37-57.

Quality Assurance Agency for Higher Education (2012). Enterprise and entrepreneurship education: guidance for higher education providers in England Wales and Northern Ireland, QAA, Gloucester.

Rae, D. (2009), 'Connecting entrepreneurial and action learning in student-initiated new business ventures: the case of SPEED' Action Learning: Research \& Practice, Issue 6(3) pp289-304.

Rae, D. (2010), 'Universities and enterprise education: responding to the challenges of the new era.' Journal of Small Business and Enterprise Development, Vol. 17 No. 4, pp. 591-60 Wilson, T. (2012), Review of HE-business collaboration,

http://www.wilsonreview.co.uk/review/ 